\section{Conjunctival Tumors}

Saeed Alwadani

Departmeny of Ophthalmology, King Saud University, Riyadh, Saudi Arabia

\section{Definition}

Conjunctival tumors are a large and varied spectrum of disorders ranging from benign to malignant lesions.

\section{Basic Characteristics}

The majority of conjunctiva tumors are benign and malignant tumors and are relatively rare. Conjunctival epithelial tumor is more common than stromal tumor. The former one can be classified according to the type of cells. In general, there are three basic categories of conjunctival tumors including the ones arising from the squamous epithelium, associated with melanocytes, or lymphoid cells.

1. Squamous epithelial lesions:

- Squamous papillomas
- Ocular surface squamous neoplasia

2. Melanocytic tumors:

- Nevus

- Primary acquired melanosis

- Melanoma

3. Glandular tumor:

- Oncocytoma

4. Lymphocytic lesions:

- Benign lymphoid hyperplasia

- Lymphoma

5. Other neoplasms: Tumor may occasionally arise in the conjunctiva, including neural, muscular, vascular, and fibrous tumors and metastatic lesions.

\section{Further Reading}

Eagle RC. Eye pathology: an atlas and text, 2nd edn. Wolters Kluwer, Philadelphia

Weisenthal R (2013-2014a) Section 8: external disease and cornea. In: American Academy of Ophthalmology (ed) Basic and Clinical Science Course (BCSC). American Academy of Ophthalmology, San Francisco

Weisenthal R (2013-2014b) Section 4: ophthalmic pathology and intraocular tumors. In: American Academy of Ophthalmology (ed) Basic and Clinical Science Course (BCSC). American Academy of Ophthalmology, San Francisco 